CLINICAL STUDY

\title{
The association between papillary thyroid carcinoma and histologically proven Hashimoto's thyroiditis: a meta-analysis
}

\author{
Ju-Han Lee, Younghye Kim, Jung-Woo Choi and Young-Sik Kim \\ Department of Pathology, Korea University Ansan Hospital, 516, Gojan-1 Dong, Danwon-Gu, Ansan-Si, Gyeonggi-Do 425-707, Republic of Korea \\ (Correspondence should be addressed to Y-S Kim; Email: apysk@korea.ac.kr)
}

\begin{abstract}
Objective: No consensus exists on the association between papillary thyroid carcinoma (PTC) and Hashimoto's thyroiditis (HT). To resolve this controversy, this study aimed to evaluate the relationship between the two conditions using a meta-analysis.

Methods: We searched relevant published studies using citation databases including PubMed, Embase, and ISI Web of Science. The effect sizes of clinicopathologic parameters were calculated by odds ratio $(\mathrm{OR})$, weighted mean difference, or hazard ratio (HR). The effect sizes were combined using a randomeffects model.

Results: Thirty-eight eligible studies including 10648 PTC cases were selected. Histologically proven HT was identified in 2471 (23.2\%) PTCs. HT was more frequently observed in PTCs than in benign thyroid diseases and other carcinomas $(\mathrm{OR}=2.8$ and $2.4 ; P<0.001)$. PTCs with coexisting HT were significantly related to female patients $(\mathrm{OR}=2.7 ; \mathrm{P}<0.001)$, multifocal involvement $(\mathrm{OR}=1.5$; $P=0.010)$, no extrathyroidal extension $(\mathrm{OR}=1.3 ; P=0.002)$, and no lymph node metastasis $(\mathrm{OR}=1.3 ; P=0.041)$. Moreover, PTCs with HT were significantly associated with long recurrence-free survival $(\mathrm{HR}=0.6 ; P=0.001)$.

Conclusions: Our meta-analysis showed that PTC is significantly associated with pathologically confirmed HT. PTC patients with HT have favorable clinicopathologic characteristics compared with PTCs without HT. However, patients with HT need to be carefully monitored for the development of PTC.
\end{abstract}

European Journal of Endocrinology 168 343-349

\section{Introduction}

Papillary thyroid carcinoma (PTC) is the most prevalent form of thyroid cancers, comprising about $80 \%$ of all diagnosed thyroid cancers. Hashimoto's thyroiditis (HT) - chronic lymphocytic thyroiditis or autoimmune thyroiditis - is a well-defined clinicopathologic entity and its incidence has increased over the past 50 years (1). HT is characterized by hypothyroidism, the presence of serum antithyroglobulin and antiperoxidase antibodies, and widespread lymphocytic infiltration with depletion of follicular cells. In addition to the classical HT, recent studies have proposed that IgG4-related thyroiditis may be considered as a variant of HT (2). The association between HT and PTC has been a subject of long and ongoing debate $(1,2)$.

HT has shown a wide range of occurrence from 5 to $85 \%$ in thyroid specimens resected for PTC $(3,4,5,6,7$, $8,9,10,11,12,13,14,15,16,17,18,19,20,21,22$, $23,24,25,26,27,28,29,30,31,32,33,34,35,36$, $37,38,39,40)$. In addition, the clinicopathologic characteristics of PTCs with concomitant HT have not been definitely proposed $(3,4,5,6,7,8,9,10$, $11,12,13,14,15,16,17,18,19,20,21,22,23,24$,
$25,26,27,28,29,30,31,32,33,34,35,36,37,38$, $39,40)$. Therefore, the present meta-analysis was conducted to clarify the relationship between PTCs and histologically proven conventional $\mathrm{HT}$ and to investigate the clinicopathologic features of PTCs with coexistent HT.

\section{Materials and methods}

\section{Data collection and eligibility criteria}

We searched the following online databases using the keywords 'thyroiditis' and 'cancer': i) Medline using PubMed (http://www.ncbi.nlm.nih.gov/pubmed), ii) Embase (www.embase.com), and iii) ISI Science Citation Index using the ISI Web of Science search interface (http://apps.isiknowledge.com). We also manually searched the reference lists of the identified articles. Duplicate data or overlapping articles were excluded by examining the authors' names and affiliations. The following types of articles were included: i) original articles demonstrating that the association between PTC and classical HT was assessed 
only in thyroid specimens by histopathologic examination; ii) articles published before September 2011; iii) when multiple articles were published by the same authors or institutions, the most recent or informative single article was selected. Articles lacking clinicopathologic data for meta-analysis, review articles without original data, conference abstracts, and single case reports were excluded. Study quality was independently scored by two reviewers using the Newcastle-Ottawa Scale (41). The Newcastle-Ottawa Scale is frequently used for nonrandom studies such as case-control and cohort studies. The maximum scores of case-control and cohort studies are 9 and 13 respectively. Quality scores of the 38 studies ranged from 5 to 7 with a mean of 5.9 (Table 1). All were considered adequate for metaanalysis. Neither language nor geographic restriction was defined. The selection process of the articles is shown in Fig. 1.

\section{Data pooling and statistics}

Meta-analysis was performed as previously described $(42,43)$. Briefly, effect sizes for each study were calculated by odds ratio (OR) or weighted mean

Table 1 Characteristics of individual studies included in the meta-analysis.

\begin{tabular}{|c|c|c|c|c|c|c|}
\hline References & Year & Country & Study design & Study objective & HT/PTC (\%) & $\begin{array}{l}\text { Quality } \\
\text { score }\end{array}$ \\
\hline (3) & 2011 & Korea & Case-control & Association between PTC and HT & $307 / 1028(29.9)$ & 6 \\
\hline (4) & 2010 & Italy & Case-control & Association between PTC and $\mathrm{HT}$ & $25 / 101(24.8)$ & 6 \\
\hline (5) & 2010 & Greece & Case-control & Association between PTC and HT & $12 / 32(37.5)$ & 6 \\
\hline (6) & 2009 & Italy & Case-control & $\begin{array}{l}\text { Serum thyroid autoantibody in } \\
\text { PTC with HT }\end{array}$ & $257 / 304(84.5)$ & 6 \\
\hline (7) & 2007 & Turkey & Case-control & Association between PTC and $\mathrm{HT}$ & $37 / 199(18.6)$ & 6 \\
\hline (8) & 2006 & Japan & Case-control & $\begin{array}{l}\text { Niban expression in thyroid tumor } \\
\text { and HT }\end{array}$ & $6 / 54(11.1)$ & 5 \\
\hline (9) & 2005 & Italy & Case-control & Association between PTC and HT & 19/71 (26.8) & 6 \\
\hline (10) & 2002 & Saudi Arabia & Case-control & Association between PTC and HT & $34 / 59(57.6)$ & 6 \\
\hline (11) & 1997 & Ireland & Case-control & Thyroid diseases in west Ireland & $1 / 14(7.1)$ & 6 \\
\hline (12) & 1995 & USA, Japan & Case-control & $\begin{array}{l}\text { Association between } \mathrm{PTC} \text { and } \mathrm{HT} \\
\text { in three races }\end{array}$ & $210 / 312(67.3)$ & 6 \\
\hline (13) & 1998 & USA & Case-control & Association between PTC and HT & $30 / 143(21.0)$ & 6 \\
\hline (14) & 2011 & Taiwan & Case-control & Association between PTC and HT & $85 / 1788(4.8)$ & 6 \\
\hline (15) & 2008 & USA & Case-control & Association between PTC and HT & $63 / 292(21.6)$ & 6 \\
\hline (16) & 2004 & USA & Case-control & $\mathrm{HT}$ in pediatric thyroid tumor & $3 / 6(50.0)$ & 6 \\
\hline (17) & 2002 & Argentina & Cohort & $\begin{array}{l}\text { PTC and HT in relation to iodine } \\
\text { prophylaxis }\end{array}$ & $31 / 87(35.6)$ & 7 \\
\hline$(18)$ & 1999 & USA & Case-control & Association between PTC and HT & $125 / 564(22.2)$ & 6 \\
\hline (19) & 1999 & USA & Case-control & Association between PTC and $\mathrm{HT}$ & $57 / 388(14.7)$ & 6 \\
\hline (20) & 1998 & Germany & Case- control & Association between PTC and HT & $23 / 92(25.0)$ & 6 \\
\hline (21) & 1993 & Italy & Case-control & $\mathrm{HT}$ in thyroid tumor & $4 / 22(18.2)$ & 5 \\
\hline (22) & 1983 & Italy & Case-control & $\begin{array}{l}\text { Pathologic characteristics in thyr- } \\
\text { oid cancer }\end{array}$ & $14 / 79(17.7)$ & 6 \\
\hline (23) & 1957 & USA & Case-control & $\mathrm{HT}$ in thyroid lesion & $2 / 16(12.5)$ & 6 \\
\hline (24) & 2012 & Korea & Case-control & Association between PTC and $\mathrm{HT}$ & $56 / 195$ (28.7) & 6 \\
\hline (25) & 2010 & Italy & Case-control & Association between PTC and $\mathrm{HT}$ & $128 / 343(37.3)$ & 6 \\
\hline (26) & 2010 & Korea & Case-control & Association between PTC and HT & $105 / 323(32.5)$ & 6 \\
\hline (27) & 2010 & USA & Case-control & $\begin{array}{l}\text { FoxP3+ regulatory T cell fre- } \\
\text { quency in PTC }\end{array}$ & $37 / 100(37.0)$ & 6 \\
\hline (28) & 2009 & Korea & Case-control & Association between PTC and HT & 214/1441 (14.9) & 6 \\
\hline (29) & 2009 & Korea & Case-control & BRAF mutation in PTC and HT & $37 / 101(36.6)$ & 6 \\
\hline (30) & 2009 & Norway & Case-control & PDGFC expression in PTC & $7 / 18(38.9)$ & 5 \\
\hline (31) & 2009 & Turkey & Case-control & $\begin{array}{l}\text { HT and tumor infiltrating lympho- } \\
\text { cytes in PTC }\end{array}$ & 16/61 (26.2) & 6 \\
\hline (32) & 2007 & Japan & Case-control & $\begin{array}{l}\text { Ultrasonographic finding in PTC } \\
\text { with HT }\end{array}$ & 29/83 (34.9) & 6 \\
\hline (33) & 2001 & Austria & Case-control & Latent thyroid cancer in Austria & $6 / 10(60.0)$ & 6 \\
\hline (34) & 2001 & USA & Case-control & Association between PTC and HT & $41 / 136(30.1)$ & 6 \\
\hline (35) & 1998 & Japan & Case-control & Association between PTC and HT & $281 / 1533(18.3)$ & 6 \\
\hline (36) & 1998 & Japan & Case-control & Association between PTC and $\mathrm{HT}$ & $15 / 69(21.7)$ & 6 \\
\hline (37) & 1997 & Spain & Case-control & Association between PTC and HT & $6 / 129(4.7)$ & 6 \\
\hline (38) & 1995 & Japan & Case-control & Association between PTC and $\mathrm{HT}$ & $36 / 95(37.9)$ & 6 \\
\hline (39) & 2008 & Italy & Case-control & Association between PTC and $\mathrm{HT}$ & $72 / 189(38.1)$ & 6 \\
\hline (40) & 2010 & Turkey & Case-control & Association between PTC and $\mathrm{HT}$ & $40 / 171(23.4)$ & 6 \\
\hline Total & & & & & $2471 / 10648(23.2)$ & \\
\hline
\end{tabular}

HT, Hashimoto's thyroiditis; PTC, papillary thyroid cancer. 


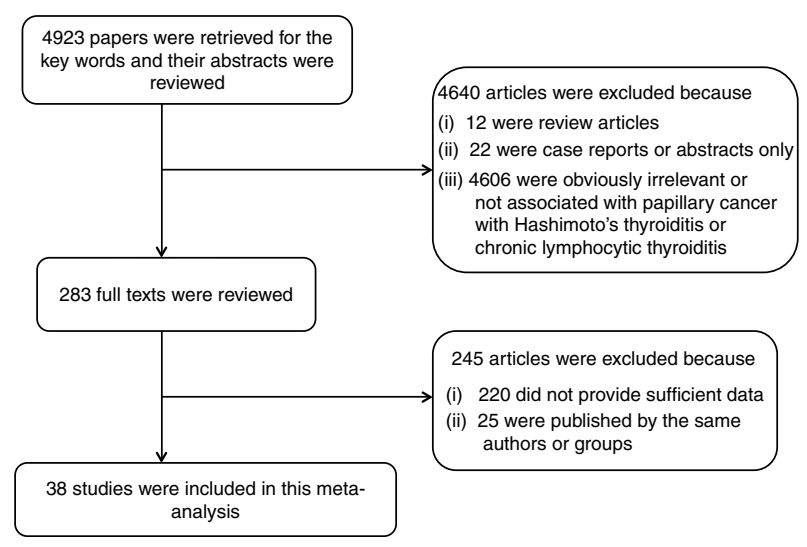

Figure 1 Flow diagram of article selection for this meta-analysis.

difference (WMD) with 95\% confidence intervals (CIs). For studies without hazard ratios (HRs) for survival, we assessed HRs and CIs using a published approximation method (44). The ORs, WMDs, or HRs were combined using a random-effects model (DerSimonian-Laird method). For identifying and quantifying inter-study heterogeneity, $Q$ statistics were calculated, which is an adaptation of the $\chi^{2}$ goodness-of-fit test. $P<0.10$ was considered statistically significant. Sensitivity analyses according to study design (case-control vs cohort studies) were performed to examine the influence of each study on the pooled OR, WMD, or HR by serially omitting an individual study and pooling the remaining studies. Publication bias was examined by funnel plots and Egger's tests for the degree of asymmetry. $P<0.05$ was considered statistically significant. The pooled analysis was conducted using Comprehensive Meta-analysis software version 2.0 (Biostat, Englewood, NJ, USA).

\section{Results}

A total of 38 articles satisfied the eligibility criteria $(3,4$, $5,6,7,8,9,10,11,12,13,14,15,16,17,18,19,20$, $21,22,23,24,25,26,27,28,29,30,31,32,33,34$, $35,36,37,38,39,40)$. The eligible studies consisted of 37 case-control studies and one cohort study, all of which were hospital based. The eligible studies are summarized in Table 1 . The number of patients in each study ranged from six to 1788 , for a total of 10648 PTC patients. Among the PTC patients, HT was present in $2471(23.2 \%)$ cases.

\section{PTC vs benign lesions}

Eleven studies compared the occurrences of HT in PTCs and in benign thyroid diseases such as nodular hyperplasia and follicular adenoma $(3,4,5,6,7,8,9$, $10,11,12,13)$. HT was found in $938(40.5 \%)$ of 2317
PTC patients, whereas it was found in $634(21 \%)$ of 3019 benign thyroid diseases. The coexistence of HT was significantly associated with PTCs than benign lesions $(\mathrm{OR}=2.766$; 95\% CI 1.947-3.929; $P<0.001)$ (Fig. 2). Significant statistical heterogeneity was found among the studies $(Q=39.664, \mathrm{df}=10, P<0.001)$.

\section{PTC vs other carcinomas}

Sixteen studies investigated the frequencies of HT in PTCs and in other carcinomas such as follicular carcinoma and medullary carcinoma $(3,5,8,10,11,13,14,15,16$, $17,18,19,20,21,22,23)$. HT was present in 797 $(17.1 \%)$ of 4664 PTC patients and in $57(7.9 \%)$ of 725 other carcinoma patients. The coexistence of HT was more related to PTCs than other thyroid carcinomas $(\mathrm{OR}=2.432$; 95\% CI 1.614-3.665; $\mathrm{P}<0.001)$ (Fig. 3). There was significant statistical heterogeneity among the studies $(\mathrm{Q}=22.727, \mathrm{df}=15, P=0.090)$.

\section{Clinicopathologic characteristics of PTCs with HT}

Gender The incidence of HT in PTCs according to gender was compared in 23 studies $(3,4,5,6,7,14$, $15,19,24,25,26,27,28,29,30,31,32,33,34,35$, $36,37,38)$. HT in PTCs was observed in 1677 of 7346 (23\%) female patients and in 180 of $573(11 \%)$ male patients. On the basis of this finding, there was a high association of HT in PTCs with females but not with males $(\mathrm{OR}=2.678 ; 95 \%$ CI 1.755-4.087; $\mathrm{P}<0.001)$. Significant statistical heterogeneity was found among the studies $(\mathrm{Q}=78.712, \mathrm{df}=22, \mathrm{P}<0.001)$.

Age Fourteen studies addressed the frequency of HT in PTCs according to patients' mean age $(3,4,5,14,24$,

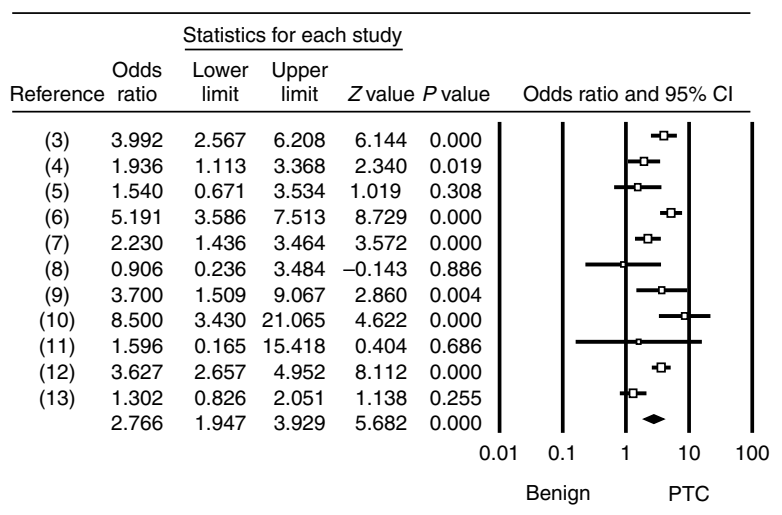

Figure 2 Odds ratios (ORs) with corresponding 95\% confidence intervals (Cls) of individual studies and pooled data for the association of Hashimoto's thyroiditis (HT) with papillary thyroid cancer (PTC), compared with benign thyroid lesions. Forest plot demonstrates the effect sizes and $95 \%$ Cls for each study and overall. 


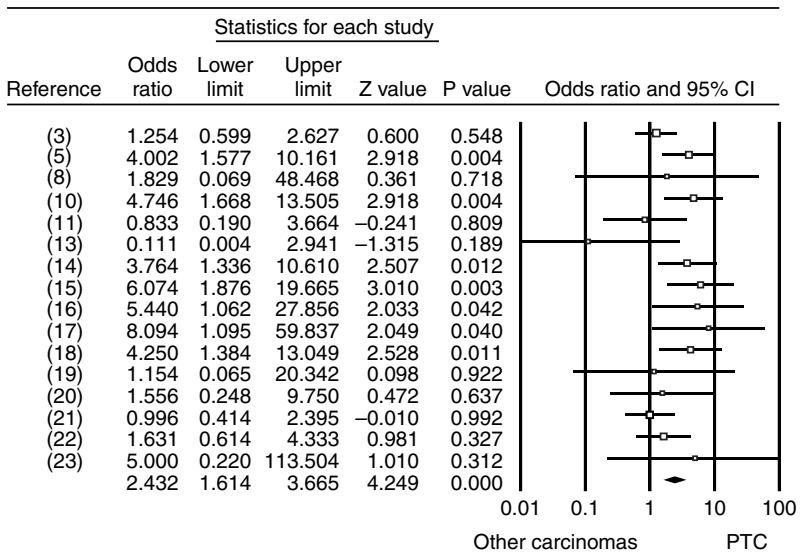

Figure 3 Pooled estimates for the frequencies of HT between PTC and other carcinomas.

$28,29,30,32,33,36,37,38,39)$. The mean ages of PTC patients with HT ranged from 39.5 to 69.0 years, whereas the mean ages of PTC patients without HT ranged from 38.2 to 56.3 years. There was no association between the mean age of PTC patients and the incidence of HT in PTC (WMD $=-0.081$; $95 \%$ CI, -0.024 to $0.042 ; P=0.195)$. Statistical heterogeneity was detected among the studies $(\mathrm{Q}=22.788, \mathrm{df}=13, \mathrm{P}=0.044)$.

Tumor size Eleven studies identified the prevalence of HT in PTCs according to average tumor size (3, 4, $14,24,28,32,33,36,37,38,39)$. The mean tumor sizes of PTCs with HT ranged from 0.6 to $4.8 \mathrm{~cm}$, whereas those of PTCs without HT ranged from 0.6 to $3.0 \mathrm{~cm}$. The tumor size was not related to the frequency of $\mathrm{HT}$ in PTC $(\mathrm{WMD}=-0.355 ; 95 \% \mathrm{CI}$, -1.224 to $0.514 ; P=0.424)$. There was statistical heterogeneity among the studies $(\mathrm{Q}=998.329, \mathrm{df}=10$, $P<0.001)$

Tumor extension Eleven studies presented 4128 PTCs without extrathyroidal extension and 2897 PTCs with extrathyroidal involvement $(3,14,19,24$, $27,28,29,35,38,39,40)$. HT was found in 722 (17.5\%) of 4128 PTCs without extrathyroidal extension and in $500(17.2 \%)$ of 2897 PTCs with extrathyroidal extension. The coexistence of HT in PTCs was associated with no extrathyroidal involvement of PTC $(\mathrm{OR}=1.295 ; 95 \%$ CI $1.098-1.527 ; P=0.002)$. No significant statistical heterogeneity was detected among the studies $(Q=11.656, \mathrm{df}=10, P=0.309)$.

Lymph node metastasis Sixteen studies reported 4185 PTC patients without lymph node metastasis and 3462 patients with lymph node metastasis $(3,4,7,14,19$, $24,25,27,28,29,30,35,37,38,39,40)$. HT was seen in $746(17.8 \%)$ of 4185 PTC cases without lymph node metastasis and in $622(17.9 \%)$ of 3462 cases with lymph node metastasis. PTCs with HT were related to the absence of lymph node metastasis $(\mathrm{OR}=1.287$; 95\% CI 1.010-1.639; $P=0.041$ ). There was significant statistical heterogeneity among the studies $(Q=29.899$, $\mathrm{df}=15, P=0.012$ ).

Multifocality Twelve studies addressed the frequencies of HT in single and multifocal PTCs (3, 4, $7,24,26,28,33,34,36,37,39,40)$. The studies included 1378 cases with multifocal PTC and 2549 cases with single PTC. HT was present in $359(26 \%)$ of 1378 multifocal PTCs and in 541 (21\%) of 2549 single PTCs. HT was more often observed in multifocal PTCs than in single PTCs $(\mathrm{OR}=1.467 ; 95 \%$ CI 1.096-1.964; $P=0.010$ ) (Fig. 4). Significant statistical heterogeneity was found among the studies $(\mathrm{Q}=23.514, \mathrm{df}=11, P=0.015)$.

Survival analysis Four studies including 616 patients of PTC with HT and 4241 of PTC without HT presented recurrence-free survival outcomes $(14,28$, $35,38)$. The estimated unadjusted HRs ranged from 0.547 to 0.781 . The presence of HT in PTCs was significantly associated with a long duration of recurrence-free survival ( $\mathrm{HR}=0.576$; 95\% CI $0.421-$ 0.790; $P=0.001$ ) (Fig. 5). There was no significant statistical heterogeneity among the studies $(Q=0.303$, $\mathrm{df}=3, P=0.960)$

\section{Sensitivity analysis and publication bias}

The sensitivity analyses revealed that all studies or casecontrol studies did not affect the pooled ORs and HR with CIs. However, seven studies influenced the result of lymph node metastasis $(4,7,14,29,30,37,40)$. In the funnel plots and the Egger's regression tests, there was no evidence of publication bias (Fig. 6).

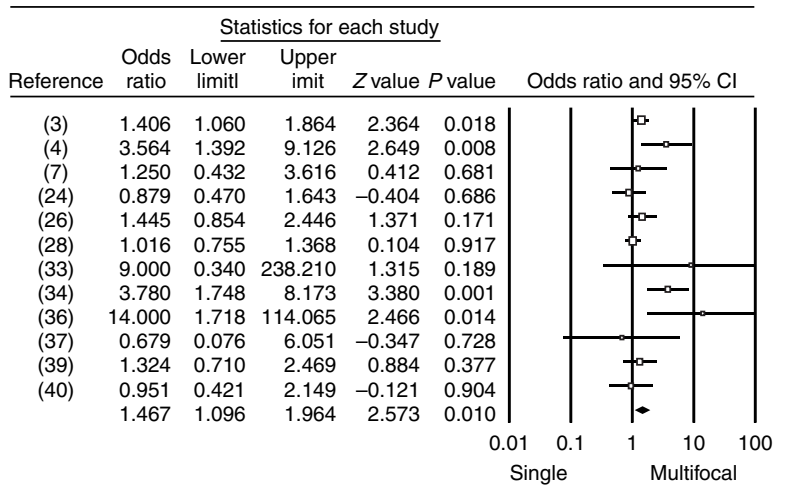

Figure 4 Pooled estimates for the frequencies of HT between single and multifocal PTCs. 


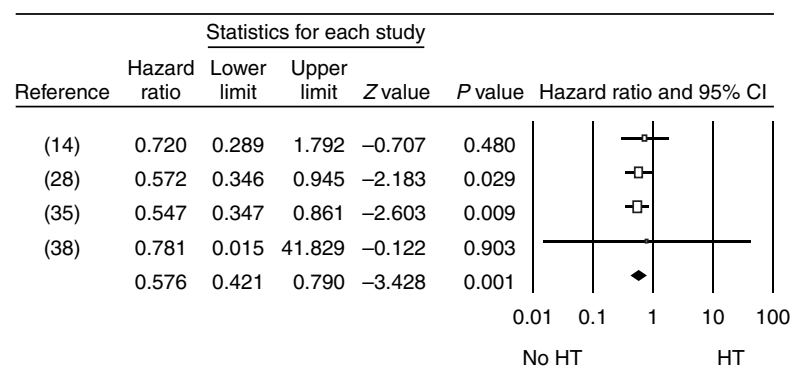

Figure 5 Hazard ratios with corresponding $95 \%$ Cls of individual studies and the pooled data for recurrence-free survival rates of PTC patients according to the presence or absence of HT.

\section{Discussion}

This meta-analysis showed that pathologically confirmed HT is more often found in PTC than in benign thyroid diseases and other carcinomas. Moreover, this analysis revealed that PTCs with coexisting HT are associated with female, multifocal involvement, the absence of extrathyroidal extension, no lymph node metastasis, and high recurrence-free survival rates.

Our pooled analysis indicates that the frequency of HT in PTCs was about $23 \%$, ranging from 5 to $85 \%$. The varying incidence rates of HT in PTC may be due to several factors such as different diagnostic criteria for HT, various surgical procedures, and heterogeneous patient characteristics. Most studies presented the incidence of HT in surgically resected PTC cases. In cytology specimens of HT patients, follicular cells often

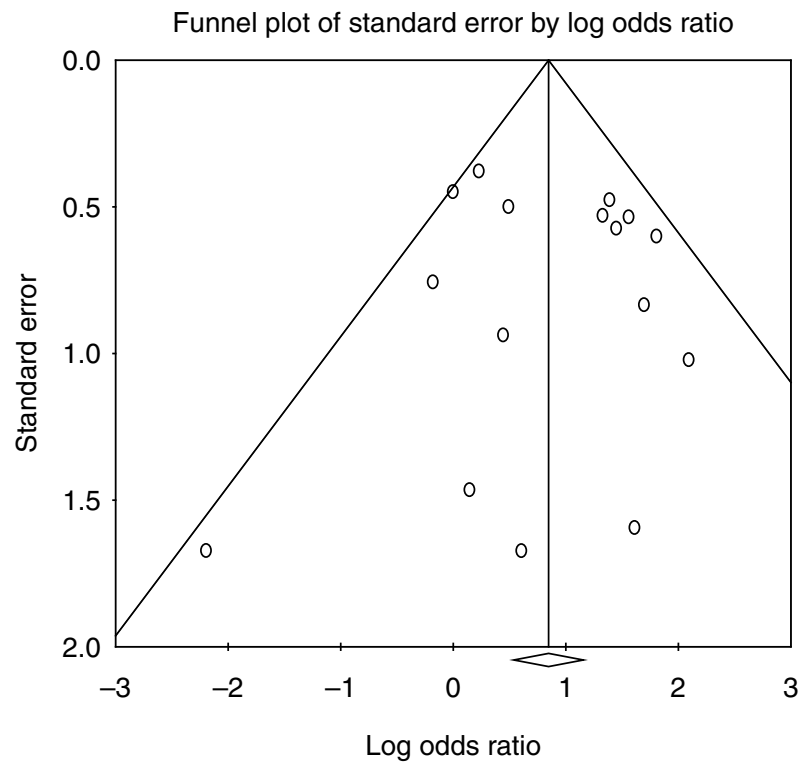

Figure 6 Funnel plot for publication bias in the incidence of HT between PTCs and other thyroid carcinomas. Individual studies are represented by small circles. exhibit nuclear elongation, nuclear grooves, and even intranuclear inclusions, leading to a misdiagnosis of PTC $(45,46)$. Therefore, the current meta-analysis included only the studies that presented cases of HT confirmed by histopathologic diagnosis.

Our meta-analysis showed that the occurrence rate of HT in PTC patients was 2.8 times higher than HT patients in benign thyroid diseases. In addition, the incidence of HT in patients with PTC was 2.4 times higher than in those patients with other types of thyroid carcinoma. This result was similar to a previous result of another meta-analysis (19). In addition, some studies supported the tight association between HT and PTC, based on the fact that RET/PTC rearrangements were found in about $90 \%$ of HT cases (47) and transgenic mice expressing RET/PTC developed HT and PTCs (48).

Interestingly, this meta-analysis revealed that PTC patients with coexisting HT had distinctive clinicopathologic characteristics such as female gender, multifocality, no extrathyroidal extension, no lymph node metastasis, and long recurrence-free survival. Considerable controversy exists concerning the prognostic significance of HT in PTC patients. Loh et al. (18) and Yoon et al. (24) reported that PTC with HT was significantly associated with females and a lower incidence of extrathyroidal invasion and lymph node metastasis. Several studies found that PTC with HT had a tendency for multifocal involvement $(3,4,26,34)$. In contrast, other studies failed to present any significant clinicopathologic characteristics in PTC with HT $(5,25,40)$.

This pooled analysis identified a paradoxical role of HT in the development and progression of PTC. The meta-analysis suggests a possible tight link between HT and the development of PTC rather than a chance occurrence of two relatively common diseases. Paradoxically, HT in PTC patients appears to play a role in impeding cancer progression. Therefore, the cross-link of these two conditions may represent a cause and effect relationship or a predisposing factor. It is hypothesized that PTC is induced or facilitated by a pre-existing lymphocytic infiltration. Conversely, lymphocytic infiltration of HT may be due to autoimmune thyroiditis and/or immune reaction to tumor-specific antigens from a pre-existing PTC (1).

\section{Conclusions}

Our pooled study indicates a close relationship between HT and PTC. As the incidence of HT is increased in PTC patients, careful clinical monitoring for the patients with HT and meticulous histopathologic examination of surgical specimens from these patients are required. The PTCs with HT are characterized by female predominance, multifocality, no extrathyroidal extension, no lymph node metastasis, and better recurrencefree survival outcomes. 


\section{Declaration of interest}

The authors declare that there is no conflict of interest that could be perceived as prejudicing the impartiality of the research reported.

\section{Funding}

This study was supported by a Korea University Grant.

\section{Author contribution statement}

J-H Lee performed statistical analyses and wrote the manuscript draft. Y Kim and J-W Choi performed the literature search and data collection. Y-S Kim designed this study and edited the manuscript.

\section{References}

1 Antonaci A, Consorti F, Mardente S \& Giovannone G. Clinical and biological relationship between chronic lymphocytic thyroiditis and papillary thyroid carcinoma. Oncology Research 200917 495-503. (doi:10.3727/096504009789735431)

2 Ahmed R, Al-Shaikh S \& Akhtar M. Hashimoto's thyroiditis: a century later. Advances in Anatomic Pathology 201219 181-186. (doi:10.1097/PAP.0b013e3182534868)

3 Kim KW, Park YJ, Kim EH, Park SY, Park do J, Ahn SH, Jang HC \& Cho BY. Elevated risk of papillary thyroid cancer in Korean patients with Hashimoto's thyroiditis. Head \& Neck 201133 691-695. (doi:10.1002/hed.21518)

4 Consorti F, Loponte M, Milazzo F, Potasso L \& Antonaci A. Risk of malignancy from thyroid nodular disease as an element of clinical management of patients with Hashimoto's thyroiditis. European Surgical Research 201045 333-337. (doi:10.1159/000320954)

5 Mazokopakis EE, Tzortzinis AA, Dalieraki-Ott EI, Tsartsalis AN, Syros PK, Karefilakis CM, Papadomanolaki MG \& Starakis IK. Coexistence of Hashimoto's thyroiditis with papillary thyroid carcinoma. A retrospective study. Hormones 2010 9 312-317.

6 Fiore E, Rago T, Scutari M, Ugolini C, Proietti A, Di Coscio G, Provenzale MA, Berti P, Grasso L, Mariotti S et al. Papillary thyroid cancer, although strongly associated with lymphocytic infiltration on histology, is only weakly predicted by serum thyroid autoantibodies in patients with nodular thyroid diseases. Journal of Endocrinological Investigation 200932 344-351.

7 Kurukahvecioglu O, Taneri F, Yuksel O, Aydin A, Tezel E \& Onuk E. Total thyroidectomy for the treatment of Hashimoto's thyroiditis coexisting with papillary thyroid carcinoma. Advances in Therapy 200724 510-516. (doi:10.1007/BF02848773)

8 Matsumoto F, Fujii H, Abe M, Kajino K, Kobayashi T, Matsumoto T, Ikeda K \& Hino O. A novel tumor marker. Niban, is expressed in subsets of thyroid tumors and Hashimoto's thyroiditis. Human Pathology 200637 1592-1600. (doi:10.1016/j.humpath.2006. 06.022)

9 Cipolla C, Sandonato L, Graceffa G, Fricano S, Torcivia A, Vieni S, Latteri S \& Latteri MA. Hashimoto's thyroiditis coexistent with papillary thyroid carcinoma. American Surgeon 200571 874-878.

10 Tamimi DM. The association between chronic lymphocytic thyroiditis and thyroid tumors. International Journal of Surgical Pathology 200210 141-146. (doi:10.1177/10668969020 1000207)

11 O'Hanlon DM, Little MP, Given HF \& Quill DS. Thyroid disease in the west of Ireland: an atypical incidence of neoplasia. Irish Medical Journal 199790 70-71.

12 Okayasu I, Fujiwara M, Hara Y, Tanaka Y \& Rose NR. Association of chronic lymphocytic thyroiditis and thyroid papillary carcinoma. A study of surgical cases among Japanese, and white and African Americans. Cancer 199576 2312-2318. (doi:10.1002/ 1097-0142(19951201)76:11<2312::AID-CNCR2820761120 $>3.0 . \mathrm{CO} ; 2-\mathrm{H})$
13 McLeod MK, East ME, Burney RE, Harness JK \& Thompson NW. Hashimoto's thyroiditis revisited: the association with thyroid cancer remains obscure. World Journal of Surgery $1988 \mathbf{1 2}$ 509-516. (doi:10.1007/BF01655435)

14 Huang BY, Hseuh C, Chao TC, Lin KJ \& Lin JD. Well-differentiated thyroid carcinoma with concomitant Hashimoto's thyroiditis present with less aggressive clinical stage and low recurrence. Endocrine Pathology 201122 144-149. (doi:10.1007/s12022011-9164-9)

15 Repplinger D, Bargren A, Zhang YW, Adler JT, Haymart M \& Chen H. Is Hashimoto's thyroiditis a risk factor for papillary thyroid cancer? Journal of Surgical Research 2008150 49-52. (doi:10.1016/j.jss.2007.09.020)

16 Van Savell H Jr, Hughes SM, Bower C \& Parham DM. Lymphocytic infiltration in pediatric thyroid carcinomas. Pediatric and Developmental Pathology 20047 487-492. (doi:10.1007/s10024-0033028-3)

17 Harach HR, Escalante DA \& Day ES. Thyroid cancer and thyroiditis in Salta, Argentina: a 40-yr study in relation to iodine prophylaxis. Endocrine Pathology 200213 175-181. (doi:10.1385/EP:13: 3:175)

18 Loh KC, Greenspan FS, Dong F, Miller TR \& Yeo PP. Influence of lymphocytic thyroiditis on the prognostic outcome of patients with papillary thyroid carcinoma. Journal of Clinical Endocrinology and Metabolism 199984 458-463. (doi:10.1210/jc.84.2.458)

19 Singh B, Shaha AR, Trivedi H, Carew JF, Poluri A \& Shah JP. Coexistent Hashimoto's thyroiditis with papillary thyroid carcinoma: impact on presentation, management, and outcome. Surgery 1999 126 1070-1076. (doi:10.1067/msy.2099.101431)

20 Schaffler A, Palitzsch KD, Seiffarth C, Hohne HM, Riedhammer FJ, Hofstadter F, Scholmerich J \& Ruschoff J. Coexistent thyroiditis is associated with lower tumour stage in thyroid carcinoma. European Journal of Clinical Investigation 199828 838-844. (doi:10.1046/j.1365-2362.1998.00363.x)

21 Mancini A, Rabitti C, Conte G, Gullotta G \& De Marinis L. Lymphocytic infiltration in thyroid neoplasms. Preliminary prognostic assessments. Minerva Chirurgica 199348 1283-1288.

22 Baroni CD, Manente L, Maccallini V \& Di Matteo G. Primary malignant tumors of the thyroid gland. Histology, age and sex distribution and pathologic correlations in 139 cases. Tumori $198369205-213$.

23 Peterson CA. Lymphocytic thyroiditis in 757 thyroid operations. American Journal of Surgery 195794 223-228 (228-231). (doi:10.1016/0002-9610(57)90649-9)

24 Yoon YH, Kim HJ. Lee JW, Kim JM \& Koo BS. The clinicopathologic differences in papillary thyroid carcinoma with or without co-existing chronic lymphocytic thyroiditis. European Archives of Oto-Rhino-Laryngology 2012269 1013-1017. (doi:10.1007) s00405-011-1732-6)

25 Muzza M. Degl'Innocenti D, Colombo C, Perrino M, Ravasi F Rossi S, Cirello V, Beck-Peccoz P, Borrello MG \& Fugazzola L. The tight relationship between papillary thyroid cancer, autoimmunity and inflammation: clinical and molecular studies. Clinical Endocrinology 201072 702-708. (doi:10.1111/j.13652265.2009.03699.x)

26 Kim HS, Choi YJ \& Yun JS. Features of papillary thyroid microcarcinoma in the presence and absence of lymphocytic thyroiditis. Endocrine Pathology 201021 149-153. (doi:10.1007/ s12022-010-9124-9)

27 French JD, Weber ZJ, Fretwell DL, Said S, Klopper JP \& Haugen BR. Tumor-associated lymphocytes and increased FoxP3 + regulatory $\mathrm{T}$ cell frequency correlate with more aggressive papillary thyroid cancer. Journal of Clinical Endocrinology and Metabolism 201095 2325-2333. (doi:10.1210/jc.2009-2564)

28 Kim EY, Kim WG, Kim WB, Kim TY, Kim JM, Ryu JS, Hong SJ, Gong G \& Shong YK. Coexistence of chronic lymphocytic thyroiditis is associated with lower recurrence rates in patients with papillary thyroid carcinoma. Clinical Endocrinology 200971 581-586. (doi:10.1111/j.1365-2265.2009.03537.x)

29 Kim SK, Song KH, Lim SD, Lim YC, Yoo YB, Kim IS \& Hwang TS Clinical and pathological features and the BRAF(V600E) mutation 
in patients with papillary thyroid carcinoma with and without concurrent Hashimoto's thyroiditis. Thyroid 200919 137-141. (doi:10.1089/thy.2008.0144)

30 Bruland O, Fluge O, Akslen LA, Eiken HG, Lillehaug JR, Varhaug JE \& Knappskog PM. Inverse correlation between PDGFC expression and lymphocyte infiltration in human papillary thyroid carcinomas. BMC Cancer 20099 425. (doi:10.1186/ 1471-2407-9-425)

31 Onak Kandemir N, Barut F, Keser S, Karadayi N, Bektaş S, Dogan Gün BB, Bahadir B, Yurdakan G \& Özdamar ŞO. Chronic lymphocytic thyroiditis and tumor-infiltrating lymphocytes combined in thyroid papillary carcinoma. Türk Onkoloji Dergisi 2009 24 172-176.

32 Ohmori N, Miyakawa M, Ohmori K \& Takano K. Ultrasonographic findings of papillary thyroid carcinoma with Hashimoto's thyroiditis. Internal Medicine 200746 547-550. (doi:10.2169/ internalmedicine.46.1901)

33 Neuhold N, Kaiser H \& Kaserer K. Latent carcinoma of the thyroid in Austria: a systematic autopsy study. Endocrine Pathology 2001 12 23-31. (doi:10.1385/EP:12:1:23)

34 Kebebew E, Treseler PA, Ituarte PH \& Clark OH. Coexisting chronic lymphocytic thyroiditis and papillary thyroid cancer revisited. World Journal of Surgery 200125 632-637. (doi:10.1007/ s002680020165)

35 Kashima K, Yokoyama S, Noguchi S, Murakami N, Yamashita H, Watanabe S, Uchino S, Toda M, Sasaki A, Daa T et al. Chronic thyroiditis as a favorable prognostic factor in papillary thyroid carcinoma. Thyroid 1998 8 197-202. (doi:10.1089/thy.1998.8.197)

36 Asanuma K, Sugenoya A, Kasuga Y, Itoh N, Kobayashi S \& Amano J. The relationship between multiple intrathyroidal involvement in papillary thyroid carcinoma and chronic non-specific thyroiditis. Cancer Letters $1998 \mathbf{1 2 2}$ 177-180. (doi:10.1016/ S0304-3835(97)00398-4)

37 Gomez Saez JM, Gomez Arnaiz N, Sahun de la Vega M \& Soler Ramon J. Prevalence and significance of lymphocyte infiltration in papillary carcinoma of the thyroid gland. Anales de Medicina Interna $1997 \mathbf{1 4} 403-405$.

38 Matsubayashi S, Kawai K, Matsumoto Y, Mukuta T, Morita T, Hirai K, Matsuzuka F, Kakudoh K, Kuma K \& Tamai H. The correlation between papillary thyroid carcinoma and lymphocytic infiltration in the thyroid gland. Journal of Clinical Endocrinology and Metabolism 199580 3421-3424. (doi:10.1210/jc.80.12.3421)

39 Del Rio P, Cataldo S, Sommaruga L, Concione L, Arcuri MF \& Sianesi M. The association between papillary carcinoma and chronic lymphocytic thyroiditis: does it modify the prognosis of cancer? Minerva Endocrinologica 200833 1-5.
40 Gul K, Dirikoc A, Kiyak G, Ersoy PE, Ugras NS, Ersoy R \& Cakir B. The association between thyroid carcinoma and Hashimoto's thyroiditis: the ultrasonographic and histopathologic characteristics of malignant nodules. Thyroid $2010 \mathbf{2 0} 873-878$. (doi:10.1089/thy.2009.0118)

41 Wells GA, Shea B, O'Connell D, Peterson J, Welch V, Losos M \& Tugwell P. The Newcastle-Ottawa Scale (NOS) for assessing the quality of nonrandomised studies in meta-analyses. Ottawa, Ontario: Ottawa Health Research Institute, University of Ottawa, 2000.

42 Lee JH, Lee ES \& Kim YS. Clinicopathologic significance of BRAF V600E mutation in papillary carcinomas of the thyroid: a metaanalysis. Cancer 2007110 38-46. (doi:10.1002/cncr.22754)

43 Lee JH, Choi JW \& Kim YS. Frequencies of BRAF and NRAS mutations are different in histological types and sites of origin of cutaneous melanoma: a meta-analysis. British Journal of Dermatology $2011 \quad 164$ 776-784. (doi:10.1111/j.1365-2133. 2010.10185.x)

44 Parmar MK, Torri V \& Stewart L. Extracting summary statistics to perform meta-analyses of the published literature for survival endpoints. Statistics in Medicine 199817 2815-2834. (doi:10. 1002/(SICI) 1097-0258(19981230)17:24<2815::AID-SIM110 $>3.0 . \mathrm{CO} ; 2-8)$

45 Feldt-Rasmussen U \& Rasmussen AK. Autoimmunity in differentiated thyroid cancer: significance and related clinical problems. Hormones 20109 109-117.

46 Haberal AN, Toru S, Ozen O, Arat Z \& Bilezikci B. Diagnostic pitfalls in the evaluation of fine needle aspiration cytology of the thyroid: correlation with histopathology in 260 cases. Cytopathology 200920 103-108. (doi:10.1111/j.1365-2303.2008. 00594.x)

47 Wirtschafter A, Schmidt R, Rosen D, Kundu N, Santoro M, Fusco A, Multhaupt H, Atkins JP, Rosen MR, Keane WM et al. Expression of the RET/PTC fusion gene as a marker for papillary carcinoma in Hashimoto's thyroiditis. Laryngoscope $1997 \mathbf{1 0 7}$ 95-100. (doi:10.1097/00005537-199701000-00019)

48 Powell DJ Jr, Russell J, Nibu K, Li G, Rhee E, Liao M, Goldstein M, Keane WM, Santoro M, Fusco A et al. The RET/PTC3 oncogene: metastatic solid-type papillary carcinomas in murine thyroids. Cancer Research $1998 \mathbf{5 8} 5523-5528$.

Received 10 September 2012

Revised version received 26 November 2012

Accepted 4 December 2012 